\title{
Left open spaces_-light shafts in Iran and side setbacks in Japan: a socio-spatial approach to study awareness in open spaces in urban residential blocks
}

\author{
Amir Shojai $^{1^{*}(0)}$ and Kaveh Fattahi ${ }^{2}$
}

\begin{abstract}
This article addresses an urban design issue at a micro-urban design level; the spaces between buildings on neighboring blocks or the side yards, how such spaces they are used, and their social impact on residents. A socio-psychological approach was taken into studying arrangements of these open spaces in contemporary residential zones in - side setback spaces in Japan, and backyards and light shafts in Iran in terms of their similarities and differences. The research involves development policies and interviews with residents in buildings where such conditions prevail, in two different contexts - Shiraz, Iran and Sapporo, Japan, two cities comparative in their size and densities for their cultural differences might have on their social responses. Seventy-two respondents in Shiraz District 6 were recruited by Shiraz University architecture students and in Japan, 75 responses were collected in Central Ward, Sapporo, from various groups of residents. Majority of the windows to side setbacks in Sapporo had matte glasses; therefore, privacy concerns were not among residents. Lack of maintenance in inner courtyards was a major concern for Iranians and they see side setbacks as a challenge to their and safety, however providing opportunities for neighborly atmosphere, if the windows have matte glasses and provided with guards. It argues that contacts are not controlled are perceived the same in two different cultures; however, the arrangement of open spaces play a role in light reception and ventilation in Japanese example.
\end{abstract}

\section{Introduction}

This article addresses a design issue at a micro-urban design level; the spaces between buildings on neighbouring plots, how they are used, and what is their social impact on residents. There is little research on the social impacts of these open spaces - yards, front yards, back yards, side yards etc. -in urban design literature. Cities become more dense as a consequence of urban intensification around the world, and people live in closer proximity to one another at higher density neighborhoods. There is a question as to how buildings and their

\footnotetext{
*Correspondence: amirshojai@gmail.com

1 Faculty of Architecture and Art, University of Kashan, Kashan, Iran Full list of author information is available at the end of the article
}

open spaces' layouts can impact social behaviour and the degree of liveability and satisfaction among neighbours.

Side yards and setback areas, as left-open spaces are framed by the residential built environment, are investigated for their influences on patterns of activity and socio-spatial relationships in neighbourhoods, and to compare their distribution within residential blocks in comparative contexts, one in Iran, and one in Japan, two societies with similar social perceptions such as exercising control over their privacy, for their benefits of ventilation and sunlight as well as their possible contribution to neighborly relations. The research involves reviewing development policies and interviews with residents in buildings where such conditions prevail, in two case studies-Shiraz, Iran and Sapporo, Japan, comparative in 
their zonning regulations, size and densities but different in how their residents perceive setback areas.

This research proposes the following questions: How do side yards and setback areas and their distribution within or surrounding residential blocks contribute to neighborly relation and residential satisfaction? And what are the relationships between their objective qualities and perceived qualities? What kind of side yards would raise its potential as a communal space?

While many urban studies have examined specific cases, in the emerging situation of similar trends in globalization, a comparative approach which can afford a general view as a whole and captures both global and local dimensions is needed.

\section{Built Environments and Residents' Satisfaction}

Studies have shown certain features of built environments are able to affect the level of residents' satisfaction (Berke et al. 2007; Cervero and Gorham 1995) and hence several factors' impacts such as residential density (Bonaiuto et al. 2003; Gauvin et al. 2005; Berke et al. 2007; Brownson et al. 2009; Hall, 2010), the general appearance of a neighborhood (Parkes et al. 2002), accessible destinations, aesthetics, access to recreational facilities and neighborhood infrastructure (Berke et al. 2007; Brownson et al. 2009; Nagel et al. 2008) have been studied. Cao (2016) in his model adopted from one of the most prevailing satisfaction frameworks namely Campbell's model (1976) focused on 3Ds (density, diversity, design) of built environment and their impacts on residents' satisfaction.

Researches above revealed that satisfaction has been linked to both physical and perceived aspects of the built environments. Physical environment influences neighborhood relation and satisfaction on various scales, whether it is presence of a large interactional space or the placement and size of a small window. Physical features of a neighborhood, such as the proximity of buildings and placement of the doors of homes, have been studied in terms of their relation with neighboring buildings, as they may facilitate interaction between residents by decreasing the distance between them (Appleyard and Lintell, 1972; Caplow and Forman, 1950).

While planners and newly arrived residents point out those physical factors are more important, longtime residents prioritize perceived factors (Lansing and Marans 1969; Potter and Cantarero 2006; Hur and Morrow-Jones 2008). Figure 1 shows several physical and perceived features that can affect neigborhood satisfaction.

In fact research findings on neighborhood satisfaction are sometimes contradictory, most likely due to the compound nature of satisfaction (Hur and Morrow-Jones 2008). While some research finds physical characteristics to have strong influence on neighborhood satisfaction compared to perceived characteristics (Sirgy and Cornwell 2002), others highlight psycho-social aspects (Amerigo and Aragones 1990). However recent studies suggests physical and perceived factors being integrated in a way that prioritizing one over the other often ignores the importance of the latter.

Therefore, it is important to study physical settings which provide social engagement and interaction while meet neighhbors' needs and expectations. These studies may suggect how such physical settings be abled to accommodate activities beyond their initial purposes and hence be considerd as interactional spaces.

\section{Yards as Interactional spaces}

Certain physical settings such as yards-front, back and side yards-or common areas such as sidewalks, are associated with high levels of casual social contact and interaction (Jacobs, 1961; Alexander et al. 1977; Marcus and Sarkissian 1986). Social interaction between neighbours is enhanced by the presence of three neighborhood variables: the opportunity for passive social contact, proximity to others and appropriate space to interact (Festinger et al. 1950; Fleming et al. 1985). The latter suggests aggregations of spatial-physical attributes in a setting, constitute a place suited for social interaction, that is a concept of interactional space (Skjaeveland and Garling 1997). The term interactional space is inspired by the term interactional territory (Lyman and Scott 1967) which refers to suitable areas temporarily controlled by a group of interacting individuals. Several concepts such as contact action space, interaction loci, social arenas (Carr et al. 1992) are comparable to interactional space. However in this paper the term interactional space has been preferred as it includes not only appearance and functional factors of a physical setting but also social activities, social perception, social identity and social representations (Stokols and Schumaker 1981; Saegert and Winkel, 1990; Bonnes et al. 1997).

Interactional spaces can encompass a wide range of physical settings, from a small bench in a front yard to a large neighborhood playground. There has been an emphasis on yards as potentially interactional spaces. Several studies investigated how yards arrangement and physical dimension influences casual social relations, pointing out that the yards features such as furniture i.e. benches and play equipment, sitting areas, open space size, planting, and fences etc. affcets interaction with neighbours (Skjaeveland and Gärling 1997). Skjaeveland and Garling (1997) emphasized four appearance aspects to be important in enhancing socializing in interactional spaces: spaciousness, enclosure, maintenance and cleanness, and, formal aesthetics and architectural properties i.e. style, 


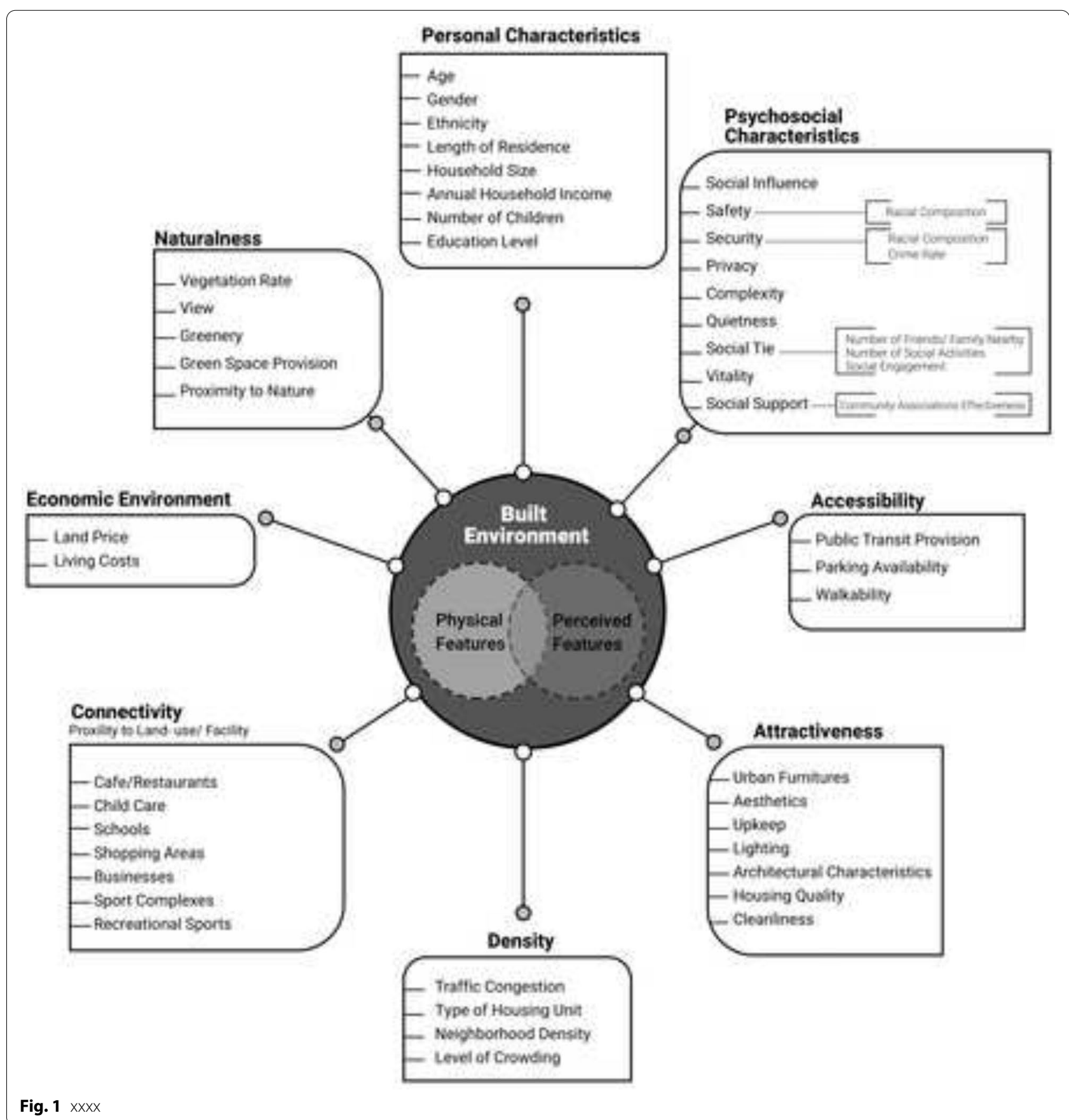

proportion and scale etc. In another research, Gifford (2007) stated that residents in higher-density neighbourhoods may choose to disengage from other residents to maintain their privacy. In similar research on Australia's Gold Coast, Buys et al. (2007) found a trend of suburban residents valuing privacy over social ties with immediate neighbours. Buys and Miller (2012) suggest that dwellings should provide maximum privacy, whereas neighbourhoods provide maximum social engagement and access (Buys and Miller 2012). Following previous studies on the effect of privacy, security, amenity, activity and usage in enhancing interactional spaces qualities, the present study will examine and analyze such features in small yards and 
setbacks in dense urban residential areas as possible interactional spaces.

\section{Setbacks}

Yards and open spaces are catagorized based on various features, one of which is their location in relation to the built spaces e.g. front yards, backyards, side yards, courtyards and setbacks. Yards are also formed based on zoning regulations. Setbacks are allowed in some urban areas while it is restricted in others. The provision of setback areas is common practice in North American development as well as in Australia, New Zealand and some Middle Eastern countries. The minimum width of side setback areas ranges from 0.9 to $2.5 \mathrm{~m}$, depending on local planning; however, this width can change according to various circumstances, for example, an addition to the existing facade or a change in building height.

Although the studies offer important insights on social properties of yards, there are still significant gaps in the field. To begin with, most of the studies focused on front yards while very few centered on backyards, side yards or setbacks and their contribution to neighborhood perception, behavior and satisfaction. That is while open spaces are gaining more attention in neighborhood studies and hence backyards, side yards and setbacks should be considered in their likely contribution in neighborhood environment and social climate. Most of existing studies on yards focus on social properties, without discussing the role of other influential factors. It is hence valuabale to study the physical features and social perceptions of setbacks in terms of neighborly relations, privacy, security, amenity, activity and usage as possible quality interactional spaces. Such studies can help decision makers, planners and stakeholders to improve neigborhood quality through benefiting from these interactional spaces beyond being perceived as left open spaces despite their importance in dense urban residential environments.

\section{Previous studies on setbacks}

Setbacks are mutual distances between two adjacent buildings generally formed by introduction of minimum setbacks in neighborhood regulations. In their suggestions for land-use policy actions toward anti-sprawl growth and greenhouse gas mitigation, Hamin and Gurran (2009) noted that smaller building setbacks are required, along with reduced street width; in order to cut the amount of car travel. Focusing predominantly on cases from the United States and Australia, they argue that wide setbacks and low density has contributed to ever increased vehicle miles travelled.

Other authors have emphasized the provision of building setbacks along with pedestrians to encourage pedestrian environments (Cervero and Gorham, 1995; Handy and Clifton, 2001; Clifton et al. 2006; Sallis et al. 2009, etc.). Greenberg et al. (1982) noted that building setbacks along with high fences have an effect on crime, affecting the ability of residents to informally survey the area. They also studied building setbacks as a measure that poses an obstacle to informal street surveillance. They showed in their results that neighborhoods with more blocks with uniform setbacks had lower crime rates. Land-use regulation, building layouts, provisions for Floor Area Ratio (FAR) levels and building shapes (which would allow light into the lots) have also been subjects of studies for their impact on land prices (more recent and relevant being Gao et al. 2006; Brueckner, 2000; Christopher and Somerville 2000). Hidano et al. (1998) evaluated building side yards regulations in terms of the increase in the number of trees, and followed this with a net benefit and cost analysis for an individual household.

On side yards, based on a 2013 survey, authors studied the physical properties of side setback areas. Their hypothesis was that there are meaningful relations between the physical properties of side setback areas or side facades and their function and perception by residents (Author). They reported the average side setback area in Sapporo (Japan) is less than 2-m wide and its typical use are for storage. Their findings indicated that side setback areas that were smaller than $1-\mathrm{m}$ wide were perceived as abandoned and assumed to have no function. However, those wider than $1-\mathrm{m}$ were seen as secondary storage areas. Regardless of this, respondents valued the light and ventilation provided by side setback areas. Possession of a terrace/balcony, a clothes-drying place, and a living/dining room window overlooking side setback areas were significantly preferred by respondents in Sapporo, followed by a neighbouring terrace/balcony, a clothes-drying space, and a large window. The respondents were generally satisfied with the ventilation and amount of light in side setback areas. Privacy concerns did not explain any of the physical elements, which can be explained by the fact that most of the windows to side setback areas had matte or patterned glass, which the residents were satisfied with, especially in kitchen windows, where respondents had not considered changing to clear glass (Author).

In another survey in an Osaka neighborhood, author noted very low frequency of use in side setbacks due to their very narrow nature. Side setbacks were perceived as dark and left-out spaces with very limited to no view and access. For those wider side setbacks, a handful of activities such as taking care of plants or taking the trash bin out were observed. The fact that almost all the windows towards the side setbacks had matte glass reassured the notion of privacy for the residents. Despite the strong community bonds in the area and the fact that most of the respondents were staying at home, respondents 
unanimously reported that they prefer to undertake social interaction at their front door and that accidental contact via their side facades were not favoured.

In a similar research for three cities in Iran, Haeri Mazandarani (2015) pointed out that setbacks were mainly perceived as left-out spaces for residents as they would not be able to connect with the space and do not feel pleasant sense of belonging.

\section{Setbacks and Zoning Regulations}

Zoning regulates lot size, floor area ratio (FAR) and height restrictions to control and regulate population density (Joshi and Kono 2009). Zoning regulations can vary and include window size, placement and orientation. Zoning also controls where the building is to be located within its boundary by delineating the required distances from street curbs, i.e. for front yards, and from other boundaries, i.e. for side yards or side setback areas. Side setback areas are therefore mutual distances between two adjacent buildings as a result of distances which both set back from their boundaries mostly due to zonning regulations. Few urban regulations allow side setback yards to be formed. Setback areas examples of side setback area provision can be found in the following references:

Japan: In urban residential districts in Japan there are minimum side setback requirements of 1-1.5 m in two categories of low-rise exclusive residential districts. However, medium-rise and high-rise residential blocks also have side setback areas mainly because in many cases, apartment blocks are built on narrow pieces of lands with the units arranged on either one or both sides of a corridor. There are nine universal categories for planning zoning in Japanese cities in the official Japanese Law Translation, the Article 8 (1) of City Planning Act (Law Number: Act No. 100 of 1968) (1948). Seven of them include residential zonings. There is a minimum 1-1.5 m minimum setback from boundary line in Category 1 and 2 Low-rise Exclusive Residential District. ${ }^{1}$

\footnotetext{
${ }^{1}$ Austalia and New Zealand.

Similar to Japan, in Australia and New Zealand the provision of keeping a side setback along plot bloudaries is stipulated in the residential development requirements:

Side and rear setback areas for residential development, Information Sheet 3.4. (January 2015) NSW Government Planning and Environment.

Planning Practice Note 27 - Understanding the Residential Development Standards (ResCode) (June 2004) State of Victoria, Department of Transport, Planning and Local Infrastructure.

Setback Requirements Residential Design Codes of Western Australia (April 2014). Residential Code Checklist - Regulations (August 2012) Government of South Australia, Department of Planning, Transportation and Infrastructure.
}

Iran: The minimum of 12 square meters $(3 \times 4 \mathrm{~m})$ for those backyards providing light for living spaces are still kept in the new developments. 6 square-meters $(2 \times 3 \mathrm{~m})$ for those backyards which provide light for kitchen or storage spaces for buildings of five stories or less.

\section{Methodology and sampling criteria}

This study is a continuation of previous studies to comapre the physical and perceived features of different side setbacks to understand what are the important factors that allow side setbacks to become better interactional spaces. There are many intervening factors that affect side setbacks and how they are being percieved and used. Accordingly for this specific study the following criteria have been set to decide case studies:

1. Case studies should be selected from those contexts in which zoning regulations specifically include side setbacks.

2. As social interactions are mostly culturally oriented, two different neighborhoods in two different cultural contexts with similar population size and density were selected.

3. To control the zoning regulations, form and size impacts, both selected case studies setback yards had similar forms and sizes due to the similar zonning regulations.

As the result, two different neighborhoods in two different cultural contexts, Iran and Japan, with similar form and size but different in how they are being used or perceived were selected. In both cases there are minimum side setback length requirements of $1-2 \mathrm{~m}$ in the low-rise residential districts whereas both follow a general American prototype of planning in which blocks are formed in grids of houses and apartments connected to one another and creat a façade facing the streets.

Sapporo as the fifth Japanese populated cities with $1,883,027$ population was planned according to American ideas of urban development, characterized by its checkerboard of wide streets and avenues. The grid pattern, wide streets, and a clearly coherent "downtown"

\footnotetext{
ootnote 1 (continued)

Building Setbacks (Sect. 4.4.2) Rules - General Standards - General Residential, Residential Intensification Zones and Large Lot Residential Zones - Hamilton City Council. www.hamilton.govt.nz.

Proposed Auckland Unitary Plan: Fact Sheet Unitary Plan, Residential Mixed Housing Urban and Suburban zones. Auckland Council. www.auckl andcouncil.govt.nz. Section 7 - Residential Rules - Areas (March 2010) Queenstown-Lakes District Council - District Plan.
} 


\begin{tabular}{lcc}
$\begin{array}{l}\text { Table } 1 \text { Comparative } \\
\text { regulations in Shiraz and Sapporo }\end{array}$ & showing & development \\
\hline Characteristics & $\begin{array}{l}\text { Freq } \\
\text { (N 75) }\end{array}$ & $\begin{array}{l}\text { Freq } \\
\text { (N72) }\end{array}$ \\
\hline & Sapporo & Shiraz \\
Sex & 11 & 40 \\
Male & 64 & 32 \\
Female & 28 & 36 \\
Type of residence & 47 & 36 \\
House & 56 & 40 \\
Apartment & & \\
With side setback area/hayat khalvat & & \\
Activities in Living/Dining room & 68 & 64 \\
Chatting/Socializing & 66 & 66 \\
Watching TV & 54 & 31 \\
Study/Training & 65 & 43 \\
Eating & & \\
\hline
\end{tabular}

distinguish Sapporo from other major Japanese cities, as do the vernacular style and construction of its houses (Mock, 1999), which makes it a prime case study in Japan to compare with recently developed urban neighborhoods in Iranian cities and, in this case, Shiraz. Table 1 shows development regulations in residential districts in Shiraz and Sapporo. (Table 1).

Shiraz is the sixth largest city in Iran with $1,869,001$ population (2016 national census) built on a geography similar to that of Sapporo. The population in District 6 of Shiraz is 165,000 and the density is 5700 per sq. kilometer, whereas in the central ward of Sapporo, the population is 224,000 and the density is 4743 per sq. kilometer.

Setback areas between adjacent buildings in Japanese neighborhoods, okugai-kukan (Japanese for setback), and light shafts and hayat-khalvat (Persian for setback) in Shiraz houses and apartments, hereafter both referred to as "side setbacks", have been mutually studied to investigate how these small open spaces are perceived by their respective residents. hayat-khalvat in Shiraz were used as a reference in order to capture the respondents' cognitive knowledge for the questions about okugai-kukan areas in the Japanese case (Figs. 2 and 3).

It is then intended to understand what features of side setbacks mostly affect social relations between the neighbors and the neighbors' perception on these non-built open spaces in two cases. Side setbacks forms and sizes are controlled variables while physical and perceived features of privacy, security, amenity, activity and usage were selected as independent variables.

The convenience non-probability sampling method is used in both cases. Respondents in Shiraz were recruited from District 6 by Shiraz University architecture students paying door-to-door visits and approaching residents in their nearby public places. Respondents outside their residences were asked to provide their location and area code in order to verify that their location was within the boundaries of this survey. Seventy-two respondents answered the questionnaire. For the study in Japan, questionnaires were submitted to 75 respondents in Central Ward, Sapporo via mail following an initial briefing session in community centers and activity centers. Similar to Shiraz, participants voluntarily filled the questionnaires and provided their location and area code (Table 2).

In the case of the Japanese respondents, the questions targeted rooms located next to the side setback areas, and in the Iranian case, questions were asked about their windows and terraces or balconies facing their hayatkhalvats. The same questions were asked about objective properties of the windows such as the type of window glass type and the objects inside and outside the windows. The second part of the questionnaire included 35 items in the Japanese version and 45 items for Iranian respondents. This was based on five generic criteria reflecting evaluation, spatial, functional and behavioural aspects (Bonnes et al. 1997): side setback areas and hayatkhalvats functions, maintenance, neighbouring relations, doors and windows to side setback areas and the side setback areas themselves. A Likert 5-point scale was used, in which 1 means 'totally disagree' and 5 means 'totally agree.' All the respondents were asked to fill out this section of the questionnaire regardless of whether they actually had a neighbouring side setback area. This was done to examine general awareness about such side setback areas, following Canter (1983)'s notion of individuals conceptualising spaces (compared with actual users) as well as Stokols' evaluation of the quality of alternative places, which here would be an actual experience of the place.

\section{Data analysis and discussion}

Data from the perception section of both questionnaires were submitted to Factor Analysis for preliminary sets of Principal Component Analysis (PCA). KMO and Bartlett's Test were run on the 5 scales of the preliminary data for the correlation test and the sampling size (KMO sampling adequacy 0.52 for Iranian respondents and 0.51 for the Japanese, $\rho<0.01)$. Six factors were extracted using the "Screen Test" explaining 34.8\% of the data variances for the Iranian respondents, and six factors were extracted using the "Screen Test", explaining $37.6 \%$ of the data variances for the Japanese respondents.

For the Shiraz section of the study, the descriptive data for activities related to side setback areas (storage, drying clothes, and keeping plants) show that only 23 respondents had a terrace or balcony towards their hayat-khalvats, from which "drying clothes" $(\mathrm{n}=10)$ and "sitting outside" ( $n=9)$ were among the most frequent activities. 

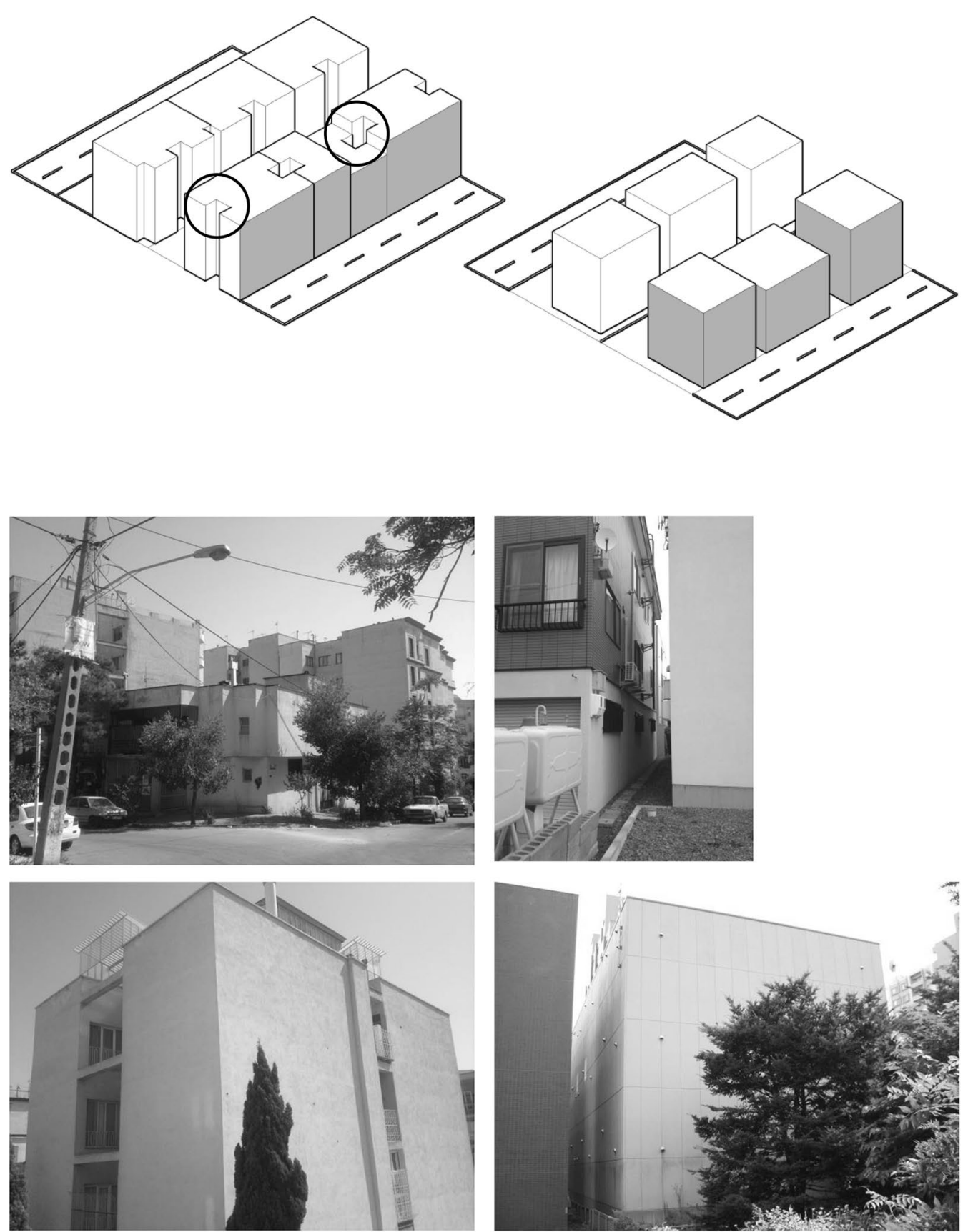

Fig. 2 (Top Left) Inner courtyards as mere light shafts in housing blocks in Iran, whereas in the Japanese case (Top Right) open spaces are shaped as side setbacks. There is a hypothesis that redistributing the open spaces in Iranian case and introduce wider inner courtyards will contribute to the better ventilation and perception of these open spaces in residential blocks (Bottom). Facades with windows are colored in grey. (Left) Hayat-khalvats as light shafts in housing blocks in Shiraz. (Right). Side setbacks in Sapporo case

Factor analysis suggests multiple related latent factors. Overall, Cronbach's Alpha for the first scale is 0.62, which is acceptable.

For the Sapporo section, the descriptive data for activities related to side setback areas (storage, car or bicycle parking, drying clothes, etc.) show that "parking cars" $(\mathrm{n}=12)$ and "gardening" $(\mathrm{n}=12)$ account for the most common activities, and the remaining activities were overwhelmingly stated to be of the minimum frequency. Factor analysis of the residents' perceptions suggests 
In Shiraz:

4 or 5 -storey (over ground floor) developments replaced earlier apartments, mainly 2 and 3 stories (shaded block). Walled facades are presented in grey.

1. The minimum of 12 square meters ( $3 \times 4$ meters) for those open spaces providing light for living spaces.

3. $60 \%$ length of the plot is fully built, in most of the cases with an extra 2 meters allowed.

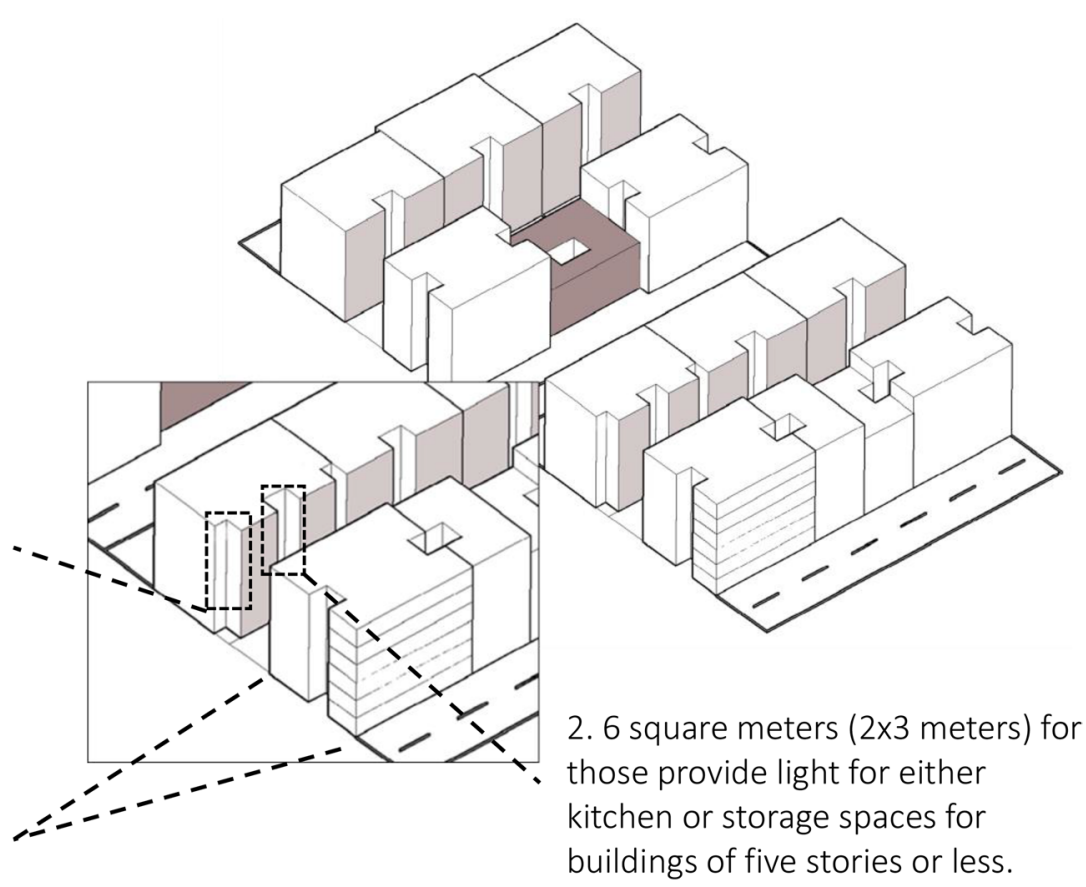

In Sapporo:

There are minimum side setback area requirements of 1-1.5 $\mathrm{m}$ in two categories of low-rise exclusive residential districts of Japanese neighborhood. However, medium-rise and high-rise residential blocks also have side setback areas mainly because in many cases, apartment blocks are built on narrow pieces of lands with the units arranged on either one or both sides of a corridor.

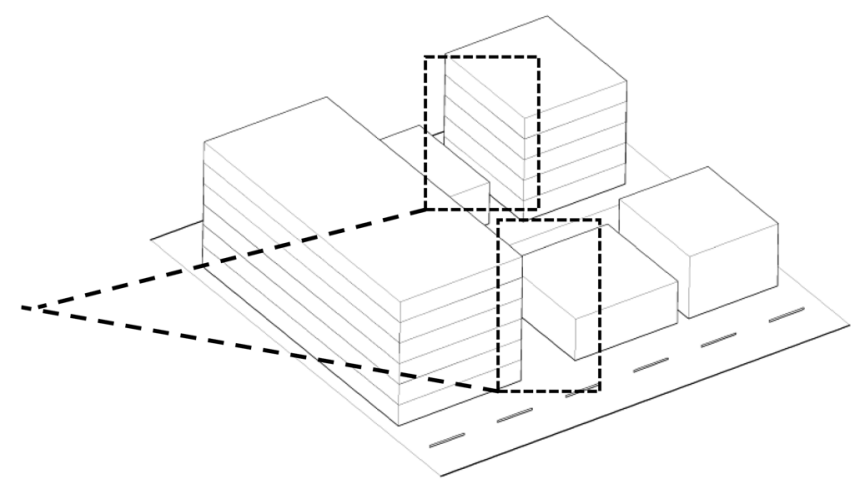

Fig. 3 (Top) Inner courtyards as mere light shafts in housing blocks in Iran, whereas in the Japanese case (Bottom) open spaces are shaped as side setbacks. There is a hypothesis that redistributing the open spaces in Iranian case and introduce wider inner courtyards will contribute to the better ventilation and perception of these open spaces in residential blocks (Bottom)

Table 2 Demographic characteristics of the sample

\begin{tabular}{lll}
\hline Location of buildings & Shiraz (District no. 6) & Sapporo (Central Ward) \\
\cline { 2 - 3 } & Northern part of the building plot in general & No provision \\
\hline Maximum BCR & $60 \%$ & Category 1 Residential \\
& $50 \%$ & Residential \\
Maximum FAR and number of floors & $30-35 \%$ & Commercial \\
& $120 \% 4$ floors & Category 1 Residential \\
& $200 \% 5$ floors & Residential \\
Minimum & $240 \%$ & Commercial \\
Setbacks/distance between buildings & Minimum 1.5-m wide and 10 sq. meter for backyards & 1-1.5 m side setbacks in Category 1 and 2 Low- \\
& for the purpose of providing light & rise Exclusive Residential \\
& No minimum side setback & \\
\hline
\end{tabular}

${ }^{a}$ Eng. Najafi, District 6 Technical Executive, Shiraz Municipality - Interview dated 15 Sep. 2014 
multiple yet poorly-related latent factors. Overall, Cronbach's Alpha for the first scale is 0.70 , which is a good result.

For the Japanese respondents, looking onto a neighboring terrace/balcony, a large window or clothes-drying spaces was tapped high in Factor 2, followed by having a terrace/balcony, clothes-drying spaces, or living/dining room windows onto side setback areas in Factor 3. Clothes-drying place refers to a small structure usually constructed of steel bars on top of the projecting first floor roofs in Japanese residential buildings, providing enough space only to step outside and hang clothes to dry out under the sun. "I have good ventilation from the window that faces the side setback area" and "enough light comes from the windows that face the side setback area" were among the subjective elements which had the highest proportion, in Factor 1. Items related to side setback areas being dark, oppressive, or abandoned were all tapped with a negative value, which showed the respondents did not have those mentioned concerns. Among those items related to appearance, "piping or wiring on the neighboring façades are done neatly" was a significant indicator in the perception of the neighborhood in Factor 1, which can be also related to occasional activities and, therefore, human presence in side setback areas.

For Iranian respondents, the results for factors had generally lower values. The results showed a large neighboring window as being one of the respondents' high priorities, in Factor 2. Preference for having a bedroom window towards the side setback areas was checked as the highest here, in Factor 2. "Having windows or balconies to side setback areas promotes neighborly ties" and "Having setbacks on all sides provides buildings with facades on, therefore making them more attractive" were checked in Factor 1; and, "Having guards is necessary for side setback areas" was checked in Factor 3 (Table 3).

In summary, both terraces/balconies and neighboring terraces/balconies were highly rated as the second factor by both groups. This suggests that the placement of terraces/balconies and clothes-drying spaces can be regarded as a preferred choice for a significant number of participants. For the Iranian example, the same function for drying clothes can be applied to terraces or balconies.

There are fairly medium relationships between the factors in both groups in general; $\mathrm{rF} 2 \mathrm{~F} 4=-0.30$ for the Iranian respondents, and rF1F2 $(-0.27)$; r F1F4 $(-0.20)$ for the Japanese. The relationship between factors for Shiraz indicates that respondents who had preferences for bedroom or living/dining room windows and a neighboring large window had opposite opinions about side setback areas as dark places and having safety issues. "Window to side setback areas should have matte glass" was checked with a negative value, which shows that respondents do not necessarily have a problem with privacy when it comes to side setback areas. The correlations between the factors for Japanese show that respondents' lower concern about smells, lack of cleanliness, and lack of privacy in side setback areas was related to the idea that side setback areas contribute to neighborhood intimacy, as well as their having an interest in looking at neighbors' windows, terrace/balconies, or clothes-drying spaces.

Multiple rounds of cross ANOVA analyses were run on the data in order to study any significant influences that physical attributes of the side façades have on the respondents' perceptions of side setback areas. On the Japanese side, there was no significant effect on the perception of the respondents whether they had or did not have side setback areas. For the Iranian respondents, however, ANOVA revealed a few significant items. The results for the significant items after the Multivariate ANOVA on the data from those with hayat-khalvats and those without hayat-khalvats show that only two items, "Side setback areas will not be kept clean" and "Smell or smoke will travel easily from side setback areas", had a lower mean for those respondents with hayat-khalvats, while the rest were higher. On the other hand, the notion that the side setback areas, windows or terraces, and balconies to side setback areas should have guards for safety had the same mean for both groups.

When asked about preferences regarding the view facing side setback areas, Japanese respondents chose clothes-drying places $(n=36)$, terrace/balcony $(n=34)$, and living/dining room $(n=29)$ and kitchen $(n=28)$ while Iranian respondents chose terrace/balcony $(n=55)$ followed by kitchen $(n=47)$. The next question, when asked about which room of the neighboring building or buildings they prefer to have their window looking towards, Japanese respondents' highest preferences were neighboring walls $(n=32)$ and green walls $(n=31)$, whereas Iranian respondents chose the neighbors' wall $(\mathrm{n}=38)$ and terrace/balcony $(\mathrm{n}=39)$ as their preferences (Table 4).

Comparing modes of preferences for both groups also revealed that Iranian respondents had higher preferences than the Japanese in general when it comes to the neighboring side façade elements. Having bedroom windows towards side setback areas were scored the lowest in both examples, which explains their concern regarding their privacy. This also explains the experience of living facing small light shafts in apartments in Iranian large cities, in which neighboring buildings stretch to the very end of their boundaries and, therefore, cannot have windows on the attached walls according to the city planning laws. Therefore, the respondents seem to prefer having a window or terrace/balcony rather than facing the wall of a neighboring building. The results from the factor analysis 
Table 3 Items for the Japanese respondents; F1F2 (- 0.27); r F1F3 (0.17); F1F4(- 0.20); F2F4 (0.02)

\begin{tabular}{|c|c|c|c|c|}
\hline & \multicolumn{4}{|l|}{ Factor } \\
\hline & 1 & 2 & 3 & 4 \\
\hline There is good ventilation from windows to side setback area & 0.74 & & & \\
\hline Enough light comes from windows facing side setback areas & 0.73 & & & \\
\hline Side setback areas are dark even during the day & -0.69 & & & \\
\hline Piping and wiring on neighboring side facades are done neatly & 0.64 & & & \\
\hline Feeling oppressed seeing neighboring buildings close by & -0.57 & & & \\
\hline Stored items in side setback areas are kept clean & 0.56 & & & \\
\hline Side setback areas are abandoned places & -0.55 & & & 0.32 \\
\hline Smell or smoke travel a lot through side setback areas & -0.49 & & & 0.43 \\
\hline There is sufficiently large setback between adjacent buildings & 0.48 & & & \\
\hline Side setback areas make residences cold during winter & -0.45 & & & 0.34 \\
\hline I can hear neighbors quite well from side setback area & -0.37 & & & 0.36 \\
\hline I always keep the curtain for my window facing side setback area closed & -0.34 & & & \\
\hline There is good air circulation in the side setback areas & 0.32 & & & \\
\hline \multicolumn{5}{|l|}{ Side setback areas are needed for balance between built and open spaces } \\
\hline \multicolumn{5}{|l|}{ Prefer to see green wall from my window facing side setback area } \\
\hline Prefer to see neighbor's terrace/balcony from my window facing side setback area & & 0.90 & & \\
\hline Prefer to see neighbor's large window from my window facing side setback area & & 0.87 & & \\
\hline Prefer to see neighbor's clothes-drying place from my window facing side setback area & & 0.84 & & \\
\hline Windows or balcony facing side setback areas are good for neighborhood intimacy & & 0.58 & & \\
\hline Prefer to see neighbor's small window from my window facing side setback area & & 0.49 & & \\
\hline \multicolumn{5}{|l|}{ Side setback areas are used as storage only } \\
\hline Prefer to have terrace/balcony facing side setback area & & & 0.90 & \\
\hline Prefer to have clothes-drying place facing side setback area & & & 0.88 & \\
\hline Prefer to have living/dining room window facing side facade & & & 0.73 & \\
\hline Prefer to have bedroom window facing side setback area & & 0.35 & 0.49 & \\
\hline Prefer to have bathroom/toilet window facing side setback area & & & 0.46 & \\
\hline Prefer to have kitchen window facing side setback area & & 0.33 & 0.46 & \\
\hline There are decorations on the windows facing side facades & & 0.31 & 0.34 & \\
\hline Prefer to see neighbor's wall from my window facing side setback area & & & 0.33 & \\
\hline Having windows facing side setback areas affect privacy & & & & 0.56 \\
\hline I try not to be seen when I am behind the window or at the balcony facing side setback areas & & & & 0.50 \\
\hline Side setback areas are good for storing bicycles etc & & & & 0.44 \\
\hline If large windows face side setback areas, it will be more observed and clean & & & 0.32 & 0.40 \\
\hline I do not look at neighbors window or terrace when I am in the side setback area & & & & 0.37 \\
\hline \multicolumn{5}{|l|}{ I pay attention to the surroundings when I open or close my window facing side setback area } \\
\hline Eigenvalue & 4.75 & 4.03 & 2.83 & 1.55 \\
\hline Explained Variances & 13.58 & 11.52 & 8.08 & 4.42 \\
\hline Total & 37.62 & & & \\
\hline
\end{tabular}

Extraction Method: Principal Axis Factoring

Rotation Method: Promax with Kaiser Normalization

of the Iranian respondents' answers also suggest that significant numbers of respondents see side setback areas as an opportunity for providing neighborly ties and intimacy, and at the same time stating that having windows towards these spaces makes them more visible and thus more likely to be kept cleaner (Table 4) (Fig. 4).

\section{Conclusion}

Activity and usege: in the current state light shafts in Shiraz are not accessible, except to the first floor residents, making the space inaccessible for the rest of the residents as well as allowing only a poor access to natural light. In Japan, side setbacks are accessible for houses and 
Table 4 Comparative Table with key quantitative findings from the survey

Comparative Table setting out key quantitative findings from the survey

\begin{tabular}{lll}
\hline & Sapporo & Shiraz \\
\hline & Parking car $(n=12)$ & Drying Clothes $(n=10)$ \\
& Gardening $(n=12)$ & Sitting Outside $(n=9)$ \\
Perception & $(+)$ & $(+)$ \\
& Ventilation & Promoting neighborly ties \\
& Light & $(-)^{*}$ \\
& $(+)$ & Smell \\
& Smell & Cleanness \\
Respondents & Cleanness & Lacades \\
Preferences & Privacy & Neoking onto \\
& Looking onto & Bare wall $(n=47)$ \\
& Bare wall $(n=32)$ & Having \\
* For those with & Terrace/balcony $(n=55)$ \\
Kitchen $(n=47)$
\end{tabular}

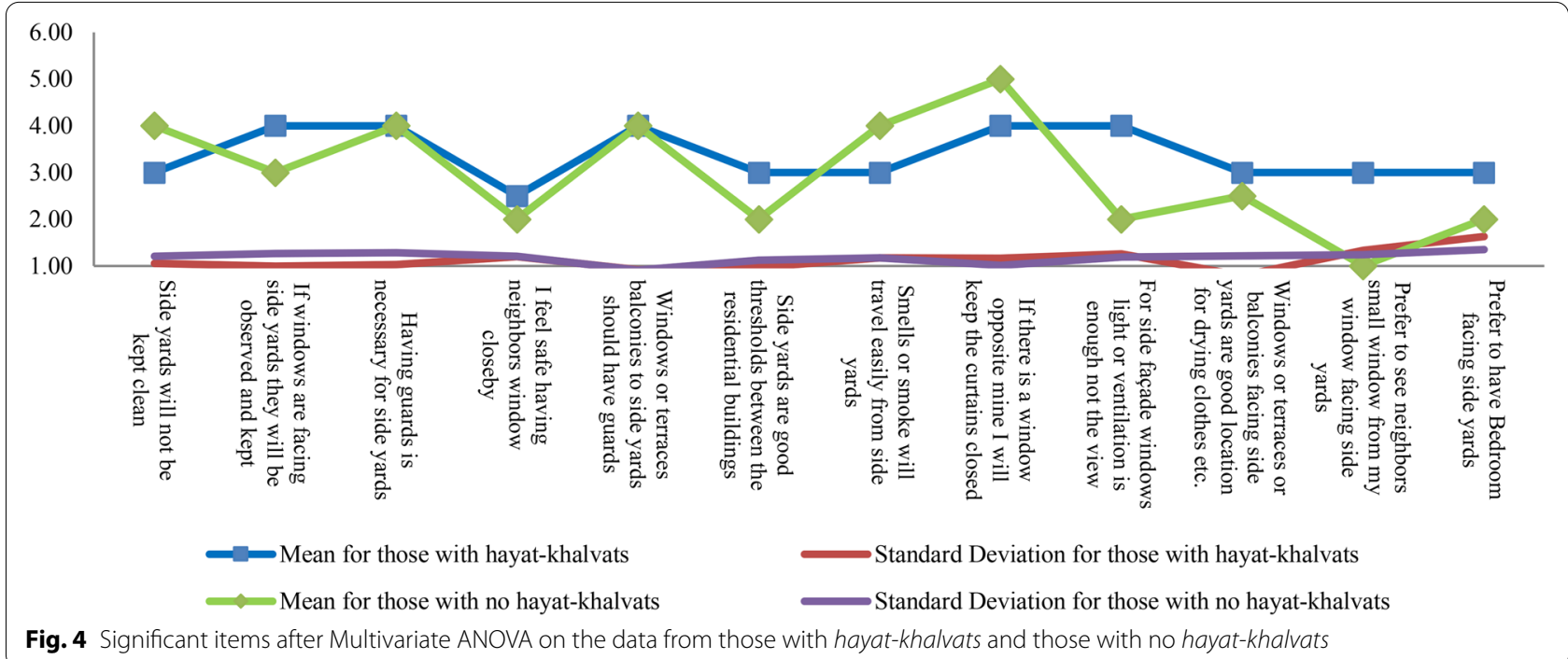

apartments for bicycle parking, small greenery spaces and other temporary usages.

High demand and profit in the Iranian housing market can explain the disappearance of open spaces such as terrace and balconies in contemporary buildings. As a result apartments stretch out to the very extent of the boundary and open spaces and setbacks have been transformed into merely 'left-out spaces' whereby only few windows open towards unplanted areas, and no activity can be take place, whereas in Japan, stability in the development of the society and the presence of consistent land-use regulations has kept the character of urban residential environment constant despite growth in land prices.

Privacy: the attitude towards privacy in Japan and Iran is similar, and the Japanese approach in providing matte glass in windows to side setback areas has contributed to fewer privacy concerns. Respondents in Japan noted that they prefer to undertake social interaction at their front door and that accidental contact via their side facades were not favoured. In Iran, the respondents anticipated side setbacks and hayat-khalvats to promote neighborly relations as culturally Iranians are more open to 

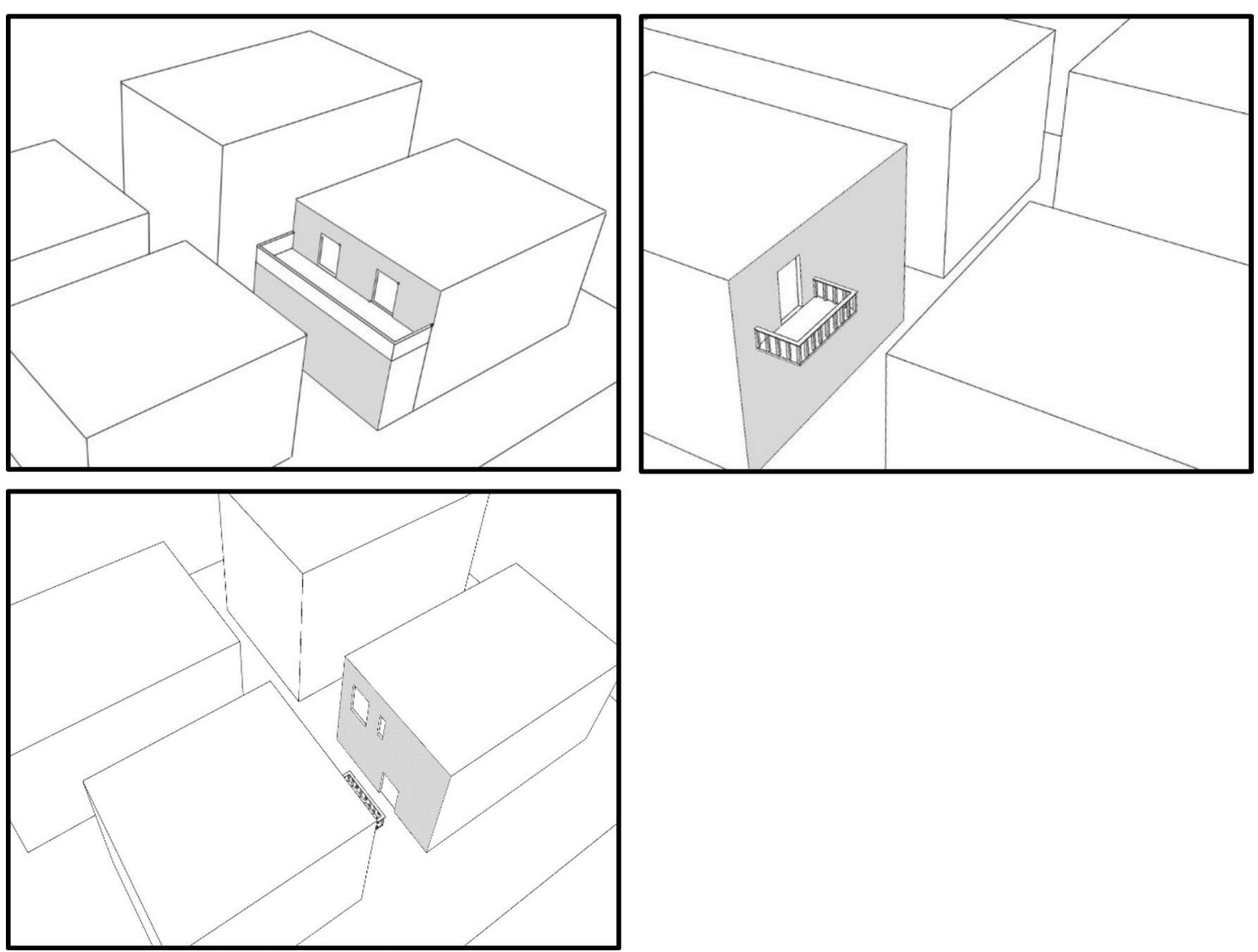

Fig. 5 Design suggestions for placing windows, terraces and balconies on side facades to promote the usage and view to these spaces

accidental contacts than the Japanese, therefore these open spaces can promote more social relations with the neighbors, given the necessary measures provided to control their privacy i.e. matte glasses, bars or windows not situated directly opposite to one another. This study suggests redistributing light shafts and possibly widening them or connecting them to street facades in order to receive more light and ventilation.

Amenity anf Security: the lack of maintenance, amenity and security in their light shafts are among issues that concern Iranian respondents the most at present. Many respondents, however, described their ideas when asked about possible activities in light shafts that were open like side setbacks, and terraces or balconies towards them, as places to rest, read, take care of plants, and prepare food, as well as, on the ground floor, for keeping children's bicycles, water faucets, and cleaning tools. Half of the respondents in Shiraz are living in apartments and all of them mentioned that they have a parking on the ground floor, and having side setbacks areas connected with parking spaces would provide additional space for children to play with their neighbors.
In order to design side setbacks beyond not built and left-out spaces, this paper recommneds design implications as follow to promote utilization of these spaces (Fig. 5):

- Wider side setback areas can provide for additional household functions as drying of clothes, gardening and household workshop related activities, provided that flat roofs or short hanging eaves ensure their enough sunlight reception.

- Side setbacks can accommodate instrumental functions ranging from storage (gas tanks, air conditioners, gardening etc.) and utility purposes (piping outlets, vents, gas and electricity meters etc.).

- Having terraces, extended verandas or clothes-drying places towards the side setback area can add extra space and enhance air circulation.

- Having Living/Dining or Kitchen windows towards side setback areas will provide side setback areas noticed as well as having less privacy issues compared to bedrooms.

- A view to a green wall or a bare wall was the major choices for the respondents, windows to side set- 
backs should be located not opposite to the neighbors' to enure their privacy.

\section{Acknowledgements}

Not applicable.

\section{Authors' contributions}

AS is the first and corresponding author. KF has contributed in data collection, literature review and supervision. Both authors read and approved the final manuscript.

\section{Funding}

Not applicable.

\section{Availability of data and materials}

Data collected for statistical analysis on this paper is available to the editors and reviewers upon request.

\section{Ethics approval and consent to participate}

The respondent in the process of data collection and interviews have expressed their consent. No personal information has been requested from the respondents during the process of data collection. All the data collected are solely used for the purpose of this research and is not available to the third part whatsoever

\section{Consent for publication}

Not applicable.

\section{Competing interests}

Not applicable.

\section{Author details}

${ }^{1}$ Faculty of Architecture and Art, University of Kashan, Kashan, Iran. ${ }^{2}$ School of Art and Architecture, Shiraz University, Shiraz, Iran.

Received: 19 February 2020 Accepted: 28 January 2021

Published online: 12 February 2021

\section{References}

Alexander C, Ishikawa S, Silverstein M, Jacobsen M, Filksdahl-King I, Angel S (1977) A Pattern Language. Oxford University Press, New York

Amerigo M, Aragones J (1990) Residential satisfaction in council housing. J Environ Psychol 10(4):313-325

Appleyard D, Lintell M (1972) Environmental quality of city streets: the residents' viewpoint. J Am Instit Planners 38:84-101

Berke E, Koepsell T, Moudon A, Hoskins R, Larson EB (2007) Association of the built environment with physical activity and obesity in older persons. Am J Public Health 97(3):486-492

Bonaiuto M, Fornara F, Bonnes M (2003) Indexes of perceived residential environment quality and neighbourhood attachment in urban environments: a confirmation study on the city of Rome. Landscape Urban Planning $65: 41-52$

Bonnes M, Bonaiuto M, Aiello A, Perugini M, Ercolani AP (1997) A transactional perspective on residential satisfaction. In: Despres C, Piché D (eds) Housing Surveys Advances in Theory and Methods. Crad, Que Canada, pp 99-135

Brownson RC, Hoehner CM, Day K, Forsyth A, Sallis JF (2009) Measuring the built environment for physical activity: State of the science. Am J Prev Med 26(4S):S99-S123

Brueckner JK (2000) Urban sprawl: diagnosis and remedies. Int Reg Sci Rev 23:160-171

Buys L, Miller E (2012) Residential satisfaction in inner urban higher-density Brisbane, Australia: role of dwelling, neighbours and neighbourhood. Environ Planning Manage 55(3):319-338

Buys L, Godber A, Summerville J, Barnett K (2007) Building community: collaborative individualism and the challenge for building social capital. Austr J Regional Stud 13(3):165-176
Canter D (1983) The purposive evaluation of places: a facet approach. Environ Behav 15:659-698

Cao X (2016) How does neighborhood design affect life satisfaction? Evidence from Twin Cities. Travel Behav Soc 5:68-76

Caplow T, Forman R (1950) Neighbourhood interaction in a homogenous community. Am Sociol Rev 15:357-366

Carr S, Francis M, Rivlin L, Stone A (1992) Public Space. Cambridge University Press

Cervero R, Gorham R (1995) Commuting in transit versus automobile neighborhoods. J Am Plan Assoc 61:2

Christopher JM, Somerville CT (2000) Land use regulation and new construction. Reg Sci Urban Econ 30:639-662

Clifton KJ, Livi Smith AD, Rodriguez D (2007) The Development and testing of an audit for the pedestrian environment. Landsc Urban Planning 80:95-110

Date visited March 3rd (2015)

Festinger L, Schachter S, Back K (1950) Social Pressure in formal groups. Holt Rinehart and Winston, New York

Fleming R, Baum A, Singer JE (1985) Social support and the physical environment. In: Cohen S, Syme SL (eds) Social Support and Health. Academic Press, Orlando

Francis M (1985) Children's use of open spaes in Village Homes. Children's Environments Quarterly 1(4):36-38

Gao X, Asami Y, Katsumata W (2006) Evaluating Land-Use Restrictions concerning the Floor Area Ratio of Lots. Environ Plan C: Gov Policy 24(4):515-532

Gauvin L, Richard L, Craig LC, Spivock M, Riva M, Forster M et al (2005) From walkability to active living potential: An "ecometric" validation study. Am J Prev Med 28(2 Suppl 2):126-133

Gifford R (2007) The consequences of living in high-rise buildings. Archit Sci Rev 50(1):2-17

Greenberg SW, Williams JR, Rohe WM (1982) Safety in Urban Neighborhoods: a comparison of physical characteristics and informal territorial control in high and low crime neighborhoods. Popul Environ 5:3

Haeri Mazandarani M (2015) House, Culture and Nature in Iranian Architecture Iran's Urbanism and Architecture Research Center Press, Tehran

Hall T (2010) The Life and Death of the Australian Backyard. CSIRO Publishing, Melbourne

Hamin EM, Gurran N (2008) Urban form and climate change: Balancing adaptation and mitigation in the U.S. and Australia. Habitat International 33:238-245

Handy SL, Clifton KJ (2001) Local shopping as a strategy for reducing automobile travel. Transportation 28:317-346

Hidano N, Kameda M, Ando S (1998) Studies on the benefit and cost of a setback regulation. Proc Japn Real Estate Institute 12:125-128

http://www.japaneselawtranslation.go.jp/law/detail/?ft $=1 \& \mathrm{re}=01 \& \mathrm{dn}=1 \& \mathrm{x}=$ $24 \& y=8 \& c 0=01 \& i a=03 \& k y=$ 都市計画法 \&page $=11$

Hur M, Morrow-Jones H (2008) Factors that influence residents' satisfaction with neighbourhoods. Environ Behav 40:619-635

Jacobs J (1961) The Death and Life of Great American Cities. Random House, New York

Joshi K, Kono T (2009) Optimization of floor area ratio regulation in a growing city. Reg Sci Urban Econ 39(4):502-511

Lansing J, Marans R (1969) Evaluation of Neighborhood Quality. J Am Inst Planners 35(3):195-199

Lyman S, Scott M (1967) Territoriality: A Neglected Sociological Dimension. Soc Probl 15(2):236-249

Marcus C (1986) Housing as if people mattered. University of California Press, Berkeley

Mock J (1999) Culture, Community and Change in a Sapporo Neighbourhood, 1925-1988. Hanyama, New York, pp 1-47

Nagel C, Carlson NE, Bosworth M, Michael YL (2008) The relationship between neighbourhood built environment and walking among older adults. Am J Epidemiol 168:461-468

Parkes A, Kearns A, Atkinson R (2002) What makes people dissatisfied with their neighbourhoods? Urban Studies 39:213-243

Potter J, Cantarero R (2006) How does increasing population and diversity affect resident satisfaction? A small community case study. Environ Behav 38(5):605-625

Saegert S, Winkel GH (1990) Environmental Psychology. Ann Rev Psychol $41: 441-477$ 
Sallis JF, Saelens BE, Frank LD, Conway TL, Slymen DJ, Cain KL, Chapman JE, Kerr J (2009) Neighborhood built environment and income: Examining multiple health outcomes. Soc Sci Med 68:1285-1293

Sirgy M, Cornwell T (2002) How Neighborhood Features Affect Quality of Life. Soc Ind Res 59:79-114

Skjaeveland O, Garling T (1997) Effects of interactional spaces on neighbouring. J Environ Psychol 17:181-198
Stokols D, Shumaker SA (1981). In: Harvey J (ed) Cognition, Social Behavior, and the Environment. Lawrence Erlbaum, Hillside, pp 441-488

\section{Publisher's Note}

Springer Nature remains neutral with regard to jurisdictional claims in published maps and institutional affiliations.

\section{Submit your manuscript to a SpringerOpen ${ }^{\odot}$ journal and benefit from:}

- Convenient online submission

- Rigorous peer review

- Open access: articles freely available online

- High visibility within the field

- Retaining the copyright to your article

Submit your next manuscript at $\boldsymbol{\nabla}$ springeropen.com 